\title{
Comparative analysis of nutrition data from national, household, and individual levels: results from a WHO-CINDI collaborative project in Canada, Finland, Poland, and Spain*
}

\author{
L Serra-Majem, D MacLean, L Ribas, D Brulé, W Sekula, R Prattala, R Garcia-Closas, \\ A Yngve, M Lalonde, A Petrasovits
}

See end of article for authors' affiliations

Correspondence to Professor L Serra-Majem, Department of Clinical Sciences, University of Las Palmas de Gran Canaria, PO Box 550, 35080 Las Palmas de Gran Canaria, Spain; Iserra@dcc.ulpgc.es

Accepted for publication 19 March 2002

\begin{abstract}
Study objective: This project determined to what extent data on diet and nutrition, which were collected in a non-uniform manner, could be harmonised and pooled for international and national comparison.

Design: Direct comparisons of dietary data between studies were made using food balance sheets (FBS), household budget surveys (HBS), and individual dietary data (IDS); comparisons were also made within countries. Differences in study design and methodological approaches were taken into consideration. Data from research projects from the following four World Health Organisation (WHO) Countrywide Integrated Noncommunicable Disease Intervention (CINDI) countries were included-Canada, Finland, Poland, and Spain.

Main results: FBS overestimated food consumption and nutrient intake compared to IDS. Results between HBS and IDS were quite similar, except for fish, meat, pulses and vegetables, which were underestimated by HBS, and sugar and honey and cereals, which were overestimated. Percentages of energy from fat, carbohydrates and proteins were higher when estimated from FBS, HBS, and IDS respectively.

Conclusions: Results suggest that estimations from these three sources of dietary data are difficult to compare because they are measuring different levels of dietary information. The understanding of their relations may be important in formulating and evaluating a nutrition policy.
\end{abstract}

sporadically conduct special individual dietary surveys (IDS) based on nationally representative population samples. Special surveys, conducted at regular intervals, could be used to describe the usual food consumption and nutrient intake patterns of the population. ${ }^{3}$ However, the high cost of these surveys has prohibited their establishment in many countries on a national level. Instead, they have only been conducted at the regional or local level or in specific population groups, and their methods have not always been the same. HBS tend to overestimate consumption of foods such as bread, potatoes, pulses, vegetables, fruit, milk, and vegetable oils as compared with individual dietary records, and to underestimate data of FBS by at least $20 \% .{ }^{45}$ Obviously, the collection of data does not necessarily imply that a nutrition policy will follow.

At present, no common international surveillance system exists permitting the comparison of nutrition and dietary risk factors that have been identified for different populations across developed countries. Although several comparative prospective cohort or cross sectional studies have been realised, ${ }^{6-16}$ almost all collected and analysed data under a standardised core protocol. Only a few projects centrally combined and analysed already existing data from European epidemiological studies, ${ }^{14-16}$ but most of them were not conducted in representative samples of the population..$^{14}{ }^{15}$ As the DAFNE (Food data networking) study has already compared data on household availability across some European countries, ${ }^{16}$ FAO

Abbreviations: FBS, food balance sheets; $\mathrm{HBS}$, household budget surveys; IDS, individual dietary surveys; CINDI, Countrywide Integrated Noncommunicable Disease Intervention 
Table 1 Dietary methods of the four participating countries

\begin{tabular}{|c|c|c|c|c|c|c|c|c|c|c|c|}
\hline \multicolumn{2}{|l|}{ FBS } & \multicolumn{4}{|l|}{ HBS } & \multicolumn{6}{|l|}{ IDS } \\
\hline Country & Years & Method & $\begin{array}{l}\text { Period } \\
\text { studied }\end{array}$ & $\begin{array}{l}\text { Sample size } \\
\text { (household) }\end{array}$ & Year & $\begin{array}{l}\text { Sample } \\
\text { size }\end{array}$ & $\begin{array}{l}\text { Age } \\
\text { groups }\end{array}$ & Sample area & $\begin{array}{l}\text { Number of } \\
\text { days }\end{array}$ & Methods & Year \\
\hline Canada & $\begin{array}{l}1990- \\
1992\end{array}$ & Record & 2 weeks & 18000 & 1990-92 & 2212 & 18 to 74 & Nova Scotia & 1 ( 2 in $30 \%)$ & $24 \mathrm{~h}$ recall & 1990 \\
\hline Finland & $\begin{array}{l}1990- \\
1992\end{array}$ & DU & DU & DU & DU & 454 & 25 to 64 & North Karelia & 3 & Food record & 1992 \\
\hline Poland & $\begin{array}{l}1990- \\
1992\end{array}$ & Food list & 3 months & 29664 & 1988 & 4440 & 20 to 65 & National industries & 1 & $24 \mathrm{~h}$ recall & 1991-94 \\
\hline Spain & $\begin{array}{l}1990- \\
1992\end{array}$ & Record & 1 week & 28000 & 1990-91 & 2757 & 6 to 75 & Catalonia & 2 & $24 \mathrm{~h}$ recall & 1992-93 \\
\hline
\end{tabular}

FBS, food balance sheets; HBS, household budget surveys, IDS: Individual dietary surveys; DU: data unavailable.

compares worldwide national food availability ${ }^{17}$ and EURODIET and EURALIM have used European IDS comparison, ${ }^{18} 19$ we compared national and household food availability with individual food consumption for inter-country and intracountry analysis.

The objectives of the study were:

- To analyse nutritional patterns and evaluate the appropriateness of comparing different levels of dietary information within a health or nutrition policy context, and

- To identify and discuss issues of international comparability of nutritional data in four CINDI countries: Canada, Finland, Poland, and Spain

\section{METHODS}

Three types of dietary information were pooled to make intercountry and intra-country comparisons: data from FBS and data from HBS at national levels and data from IDS at regional levels. Canada, Finland, Poland, and Spain provided these three levels of data, thus representing a unique opportunity to compare data across countries at three levels: national, household, and individual.

\section{Dietary information}

The Apparent Per Capita Food Consumption Data were obtained from FAO FBS, which are compiled from a wide variety of administrative data sources proceeding from Institutes of Statistics, as well as other government departments, farmers' associations, and marketing boards. Data from FBS were obtained for the years 1990, 1991, and 1992 for the four countries. $^{17}$

Family Food Expenditure was obtained from HBS. The main objective of these surveys are to review the ranking in order to calculate the consumer price index. Other objectives are to study income sources and their distribution, and also the levels and patterns of consumption and expenditure to elaborate national accounting statistics; to carry out specific analyses of areas of social interest such as housing, education, health and moreover, to analyse geographical and time trends. ${ }^{20}$ Apart from the fact that HBS collect data on food quantities purchased and not necessary consumed, another important problem is that in many cases, these data are expressed as food categories (for example, seed oils) rather than single food items (for example, olive oil) and different items are included under each food category. Additional information from various sources is needed to decide on the proportion that different food items contribute to the nutrient values in a single food category. In the context of DAFNE II, an exercise was undertaken for the conversion of foods to nutrients. The single food item level or the less aggregated food group level used was also applied in our analysis.

In Canada, the HBS from 1990 and 1992 comprised 18000 households from urban and rural areas of the 10 provinces and two territories using the Canadian Labour Force Survey Framework, a stratified multistage cluster sampling. People in reserves and institutions were excluded. Two separate instruments were used: a questionnaire and two food expenditure diaries. The questionnaire was primarily for the collection of selected socioeconomic characteristics as well as information on household purchasing habits and food expenditures. After the interview, respondents were asked to maintain a daily record of food expenditures using two one-week diaries. Methods of HBS for Finland were not included as the data were not available for this comparative study analysis. The Poland HBS included a sample size of 29664 households. Households that refused to participate were replaced by others with similar characteristics. The recording period for food expenditure was three months, and included 72 food items; fieldwork was done in 1988 and the response rate was $60 \%$. In

Table 2 Mean consumption ( $\mathrm{g} /$ person/day) of food groups derived from FBS, HBS, and IDS in four countries

\begin{tabular}{|c|c|c|c|c|c|c|c|c|c|c|c|c|c|c|c|}
\hline & \multicolumn{3}{|c|}{ Canada } & \multicolumn{3}{|c|}{ Finland } & \multicolumn{3}{|c|}{ Poland } & \multicolumn{3}{|c|}{ Spain } & \multicolumn{3}{|c|}{ Mean* } \\
\hline & FBS & HBS & IDS & FBS & HBS & IDS & FBS & HBS & IDS & FBS & HBS & IDS & FBS & HBS & IDS \\
\hline Dairy products & 586 & 348 & 337 & 910 & DU & 534 & 609 & 332 & 354 & 430 & 379 & 226 & 634 & 353 & 363 \\
\hline Meats & 273 & 108 & 141 & 180 & DU & 134 & 210 & 179 & 236 & 278 & 188 & 173 & 235 & 158 & 171 \\
\hline Fish & 61 & 11 & 37 & 89 & DU & 43 & 32 & 14 & DU & 104 & 80 & 74 & 72 & 35 & 51 \\
\hline Pulses & 18 & 5 & 8 & 1 & DU & 6 & 6 & 3 & 6 & 16 & 20 & 22 & 10 & 9 & 11 \\
\hline Nuts and oil seeds & 24 & 7 & 6 & 6 & DU & DU & 4 & DU & DU & 33 & 4 & 4 & 17 & 6 & 5 \\
\hline Eggs & 29 & 22 & 23 & 28 & DU & 26 & 27 & 26 & 22 & 41 & 35 & 27 & 31 & 28 & 25 \\
\hline Fruits & 329 & 211 & 164 & 261 & DU & 307 & 114 & 112 & 137 & 410 & 311 & 299 & 279 & 211 & 227 \\
\hline Vegetables & 296 & 160 & 146 & 152 & DU & 92 & 307 & 195 & 288 & 417 & 168 & 211 & 293 & 174 & 184 \\
\hline Roots and tubers & 165 & 74 & 103 & 209 & DU & 157 & 395 & 315 & 317 & 301 & 147 & 74 & 268 & 179 & 163 \\
\hline Cereals & 246 & 204 & 193 & 252 & DU & 205 & 414 & 309 & 227 & 279 & 245 & 166 & 298 & 253 & 198 \\
\hline Oils and fats & 69 & 36 & 33 & 50 & DU & 39 & 68 & 54 & 57 & 82 & 55 & 30 & 67 & 48 & 40 \\
\hline Sugar and honey & 125 & 42 & 39 & 109 & DU & 32 & 110 & 91 & 56 & 90 & 40 & 18 & 109 & 58 & 36 \\
\hline Alcoholic beverages & 246 & DU & 114 & 286 & DU & 120 & 140 & DU & DU & 299 & 113 & 143 & 243 & 113 & 126 \\
\hline
\end{tabular}

* Mean, average of the four countries. Abbreviations as for table 1. 
Table 3 Differences between the food group consumption estimates in each country for FBS, HBS, and IDS and the four country average

\begin{tabular}{|c|c|c|c|c|c|c|c|c|c|c|c|c|}
\hline & \multicolumn{3}{|c|}{$\begin{array}{l}\text { Canada *Difference with } \\
\text { mean } \%\end{array}$} & \multicolumn{3}{|c|}{$\begin{array}{l}\text { Finland } * \text { Difference with } \\
\text { mean } \%\end{array}$} & \multicolumn{3}{|c|}{$\begin{array}{l}\text { Poland *Difference with } \\
\text { mean } \%\end{array}$} & \multicolumn{3}{|c|}{$\begin{array}{l}\text { Spain *Difference with } \\
\text { mean } \%\end{array}$} \\
\hline & FBS & HBS & IDS & FBS & HBS & IDS & FBS & HBS & IDS & FBS & HBS & IDS \\
\hline Dairy products & -8 & -1 & -7 & 44 & DU & 47 & -4 & -6 & -2 & -32 & 7 & -38 \\
\hline Meats & 21 & -32 & -17 & -20 & DU & -21 & -7 & 13 & 39 & 23 & 19 & 2 \\
\hline Fish & -15 & -69 & -28 & 24 & DU & -16 & -55 & -60 & DU & 45 & 129 & 44 \\
\hline Pulses & 76 & -46 & -24 & -90 & DU & -43 & -41 & -68 & -43 & 56 & 114 & 110 \\
\hline Nuts and oils & 43 & 27 & 20 & -64 & DU & -100 & -76 & DU & DU & 97 & -27 & -20 \\
\hline Eggs & -7 & -20 & -6 & -10 & DU & 6 & -14 & -6 & -10 & 31 & 27 & 10 \\
\hline Fruits & 18 & 0 & -28 & -6 & DU & 35 & -59 & -47 & -40 & 47 & 47 & 32 \\
\hline Vegetables & 1 & -8 & -21 & -48 & DU & -50 & 5 & 12 & 56 & 42 & -4 & 15 \\
\hline Roots and tubers & -38 & -59 & -37 & -22 & DU & -4 & 48 & 76 & 95 & 13 & -18 & -55 \\
\hline Cereals & -17 & -19 & -2 & -15 & DU & 4 & 39 & 22 & 15 & -6 & -3 & -16 \\
\hline Oils and fats & 3 & -26 & -40 & -26 & DU & -29 & 1 & 12 & 4 & 22 & 14 & -45 \\
\hline Sugar and honey & 15 & -27 & 8 & 0 & DU & -12 & 1 & 58 & 54 & -17 & -31 & -50 \\
\hline Alcoholic beverages & 1 & $\overline{D U}$ & -9 & 18 & DU & -5 & -42 & DU & DU & 23 & 0 & 14 \\
\hline
\end{tabular}

Spain, the entire country (50 provinces) was included in the HBS. The 50 provinces were grouped into 17 autonomous regions. The study sample for these surveys was selected by a two staged stratified sampling scheme, and included 28000 households during 1990 to 1991. Trained interviewers visited the households every other day for one week. Record keeping methods were also used to collect data on household daily expenses as a whole, and for each individual family member. The 1990-1991 survey gathered food expenditure data for 257 items, including wine and alcoholic beverages. ${ }^{5}$

IDS consisted of similar methodologies because all countries used 24 hour recalls or records but not food frequency questionnaires. In Canada, the Nova Scotia Nutrition Survey was a collaborative project carried out by the provincial government and the federal Department of Health and Welfare in 1990. A stratified, two staged, replicated probability sample design was used; 2212 people aged 18 to 74 completed the interview. Information was collected on demographic data, food frequency data, dietary knowledge, opinions, and one 24 hour recall by personal interviews at home. To estimate and adjust for the intraindividual variation, a second 24 hour recall was obtained in one third of the sample. Food models were used to ascertain portion sizes. Food conversion into nutrients was calculated using the Canadian Nutrient Data Bank and the software system CANDI. ${ }^{21}$

In Finland, the FINMONICA Survey was utilised, developed by the national Public Health Institute, which comprises a random sample of 1865 (participation rate of 66\%) people aged 25 to 64 . The survey was carried out in four Finnish areas

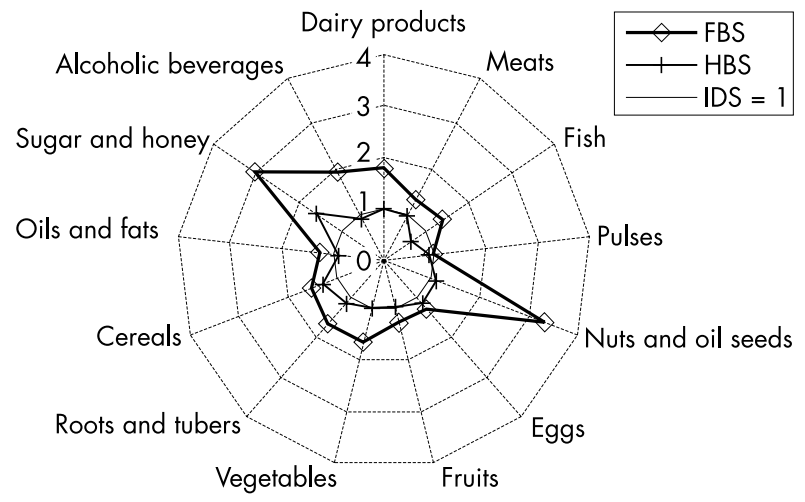

Figure 1 Estimations of food availability (FBS and HBS) and consumption (IDS) in reference to IDS calculations for the four countries average. Canada, Finland, Poland, and Spain. (results are presented only for North Karelia $n=454$ ) from January to March 1992. After attendance at the local health centre, the subjects were given instruction on how to keep a three day food record and completed records were returned by mail. For portion size estimation a picture book was used, and the NUTNET (Food Composition database of the National Public Health Institute) enabled the conversion of foods into nutrients. ${ }^{22}$

In Poland, data were collected from men and women in separate surveys. In 1994, 2238 adult men aged 20 to 65 years from a number of large industries and enterprises comprised the countrywide sample. Individual subjects were chosen at random using multistage sampling. For women, the data were collected during 1991 to 1994 from a number of large industrial plants covering all of Poland. Some 2202 women aged 20 to 65 years were chosen at random. Information was collected using a 24 hour recall method by trained interviewers. ${ }^{23}{ }^{24}$

In Spain, the Catalan Nutrition Survey was conducted by the Catalan Autonomous Government and the University of Barcelona in 1992. A two staged random sample of 2757 from 4000 people (69\% participation) aged 6 to 75 were interviewed at home by trained personnel who gathered information on food habits and other risk factors. Dietary information included food frequency questionnaire, questions on nutrition knowledge and opinions, and two 24 hour recalls, one during the cold season and the other during the summer. Household food measures were used and conversion of food into nutrients was carried out using the French Food Composition Tables. Adjustment of intraindividual variability was performed by statistical methods as done in the Canadian Survey. ${ }^{25}$

The dietary methods from the four countries are presented in table 1. All the methods refer to the same period (1990-1992) except for Poland where HBS data come from 1988.

\section{Analysis}

Data were analysed in each collaborative centre following a uniform protocol. Age groups used were as follows 25-34, 35-44, 45-54, 55-64, and 65-74 years. Average consumption of intake and percentages were age and sex standardised for the European population using the indirect method.

With respect to the food data collected by FBS, HBS, and IDS, the initial step taken by the WHO-CINDI working group was to clarify exactly what was included under each food category used by the different survey teams. It was obvious that the level of detail for recorded data varied from one country to another (except FAO-FBS, which used the same groups). Furthermore, in certain cases, food groups seemed to overlap 
Canada

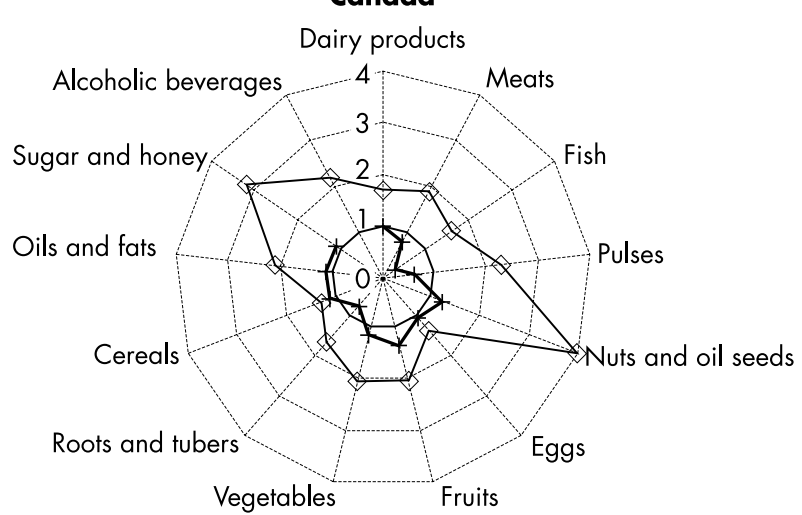

Poland

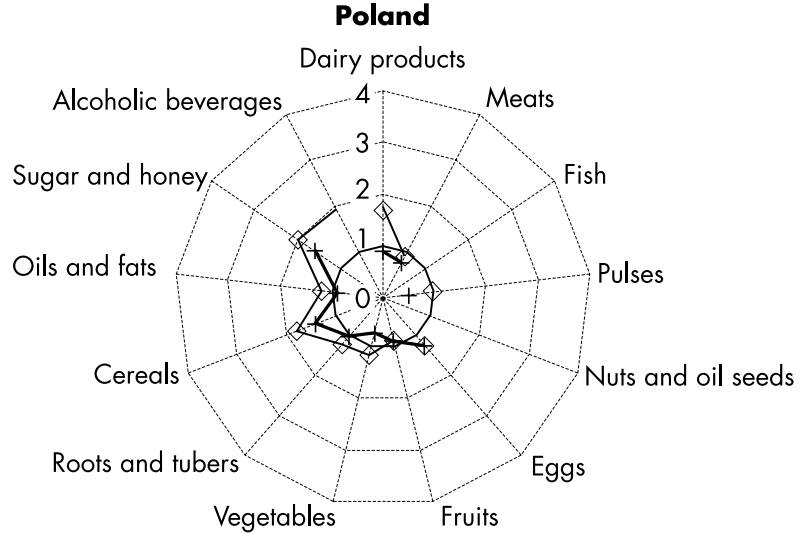

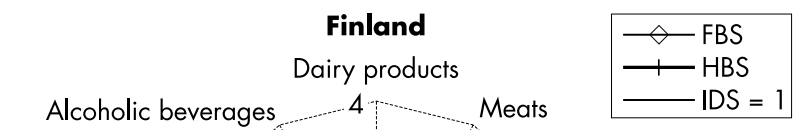
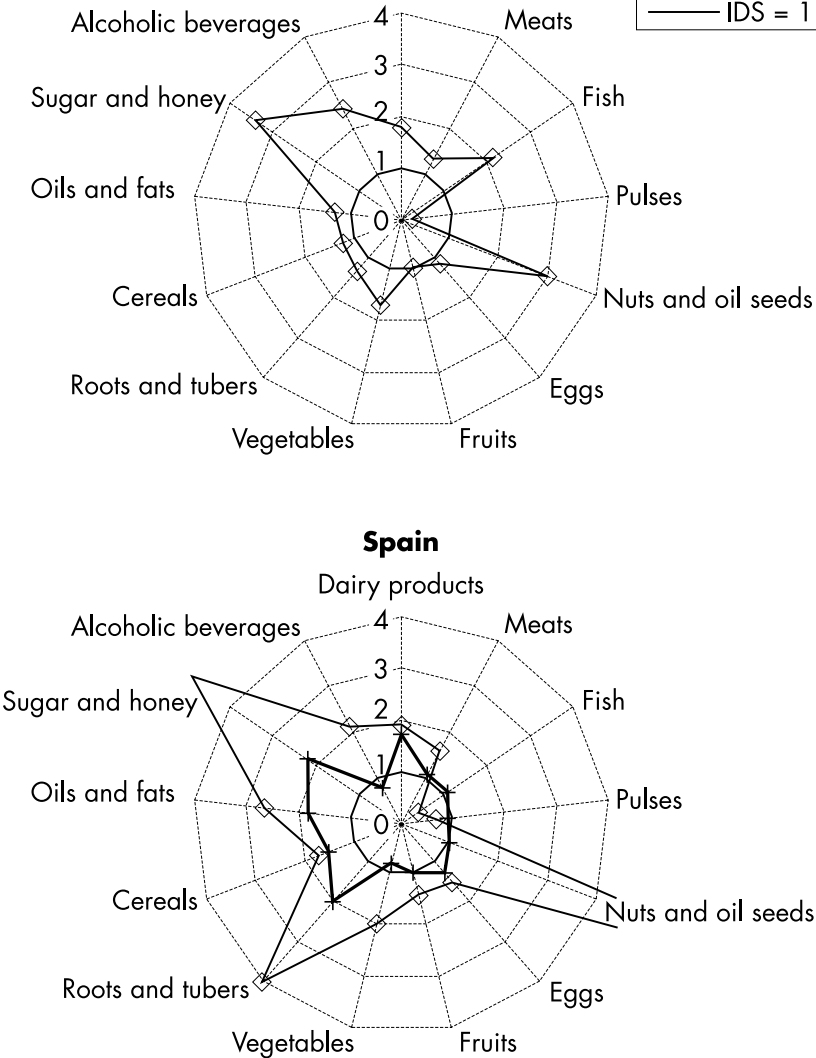

Figure 2 Estimations of food availability (FBS and HBS) and consumption (IDS) in reference to IDS in Canada, Finland, Poland, and Spain.

between countries. As the data did not share the same degree of detail, aggregations of food items to the lowest level of information became necessary. The groups that were finally selected consisted of the food groupings used in the FAO-FBS: dairy products, meats (including liver and offals), fish, pulses (beans, peas, others), nuts and oil seeds, eggs, fruits (fresh, canned, frozen), vegetables, roots and tubers (starchy roots), cereals, oils and fats, sugar and honey, and alcoholic beverages.

The internal differences (\%) of the three levels of information were calculated for each country and for the average of the three levels of dietary data among the four countries. External differences were also calculated comparing the three levels of information in each country with the four country average.

\section{RESULTS}

The mean consumption of food groups estimated by the three methods for each of the four countries and their average are shown in table 2 . As an example, dairy product consumption ranged from $910 \mathrm{~g} /$ person/day (Finland) to $430 \mathrm{~g} /$ person/day (Spain) according to FBS, and from $534 \mathrm{~g} /$ person/day (Finland) to $226 \mathrm{~g} /$ person/day (Spain) according to IDS. FBS overestimated dairy product consumption by $43 \%$ compared with IDS (the percentage being very similar across countries), and by $33 \%$ compared with HBS (from $45 \%$ to $12 \%$ ). HBS estimates were similar to IDS except for Spain. Figure 1 includes the different estimation of food availability and consumption in reference to IDS calculations for the average of the four countries and figure 2 the same information for each individual country. Table 3 compares the differences in food group consumption between national estimates and the four country average. Similarity of the percentages of the three columns could reflect better consistency of the data. Percentages were similar for certain foods: dairy products (except for
HBS in Spain), pulses (except for FBS in Canada), meats (except for IDS in Poland), nuts and oil seeds (with the exception of Spain), fruits (excluding Canada and Finland), vegetables (in Finland only), and roots and tubers (excluding Spain). In general, consistency was better for HBS and IDS than for FBS and HBS or FBS and IDS.

Table 4 shows the mean intake of energy, macronutrients, fatty acids, and alcohol. Average intakes of energy were 13728 $\mathrm{kJ} /$ person/day $(3281 \mathrm{kcal}), 10290 \mathrm{~kJ} /$ person/day $(2459 \mathrm{kcal})$, and $8843 \mathrm{~kJ} /$ person/day $(2114 \mathrm{kcal})$, and for fat 138, 104, and $84 \mathrm{~g} /$ person/day for FBS, HBS, and IDS, respectively. On average, FBS overestimated energy and fat intake by more than $35 \%$ to $40 \%$ as compared with HBS, with variations from one country to another. With the exception of Poland, percentages of energy from fat were higher in estimates from FBS, percentages of energy from proteins were higher in estimates from IDS, and excluding Canada, the percentages of energy from carbohydrates were higher in results from HBS. As compared with IDS, FBS overestimated alcohol intake by $60 \%$ to $70 \%$ in all countries.

When comparing the differences in energy and macronutrient intake between the national estimates and the four country average, percentages were very different from one method to the other. A higher degree of inconsistency was observed between these three levels of nutritional data when comparing nutritional intake or availability across countries. Figure 3 shows the comparability of energy and macronutrient intake for the three methods (average) and figure 4 shows the same for each individual country.

Food patterns clearly differ from one country to another. In Spain there was a higher consumption of fruits and vegetables, fish, and pulses. In Poland more meat, potatoes, and sugar were consumed, and in Finland more dairy products. These differences in dietary patterns were observed 
Table 4 Mean intake of energy, macronutrients, fatty acids, and alcohol derived from FBS, HBS, IDS in four countries

\begin{tabular}{|c|c|c|c|c|c|c|c|c|c|c|c|c|c|c|c|}
\hline & \multicolumn{3}{|c|}{ Canada } & \multicolumn{3}{|l|}{ Finland } & \multicolumn{3}{|l|}{ Poland } & \multicolumn{3}{|l|}{ Spain } & \multicolumn{3}{|l|}{ Mean* } \\
\hline & FBS & HBS & IDS & FBS & HBS & IDS & FBS & HBS & IDS & FBS & HBS & IDS & FBS & HBS & IDS \\
\hline Energy (kJ) & 12632 & 8849 & 8605 & 12849 & DU & 9551 & 14008 & 11000 & 8756 & 15432 & 11021 & 8461 & 13728 & 10290 & 8843 \\
\hline Energy (kcal) & 3017 & 2115 & 2057 & 3071 & DU & 2283 & 3348 & 2629 & 2093 & 3688 & 2634 & 2022 & 3281 & 2459 & 2114 \\
\hline Protein (g) & 94.8 & 81.3 & 87.2 & 97.5 & DU & 90.4 & 102.5 & 71.6 & 68.2 & 105.0 & 93.5 & 90.7 & 100.0 & 82.0 & 84.1 \\
\hline $\begin{array}{l}\text { Carbohydrates } \\
\text { (g) }\end{array}$ & 331.0 & 269.4 & 239.7 & 346.0 & DU & 282.8 & 442.0 & 344.0 & 264.9 & 364.3 & 294.0 & 201.7 & 370.8 & 302.3 & 247.3 \\
\hline Fat (g) & 128.4 & 84.6 & 80.4 & 128.5 & DU & 86.0 & 114.7 & 106.9 & 83.3 & 181.2 & 121.0 & 84.1 & 138.0 & 104.3 & 83.5 \\
\hline MUFA (g) & DU & 34.1 & 32.8 & DU & DU & 31.1 & DU & 41.8 & DU & DU & 55.2 & 38.2 & DU & 43.7 & 34.0 \\
\hline PUFA (g) & DU & 14.4 & 12.6 & DU & DU & 12.6 & DU & 18.1 & DU & DU & 19.8 & 10.3 & DU & 17.3 & 11.8 \\
\hline SAT (g) & DU & 28.4 & 28.7 & DU & DU & 39.6 & DU & 39.5 & DU & DU & 34.9 & 27.8 & DU & 34.0 & 32.0 \\
\hline Alcohol (g) & 23.0 & DU & 6.5 & 21.0 & DU & 7.8 & 19.0 & DU & DU & 26.0 & DU & 10.5 & 22.3 & DU & 8.3 \\
\hline \multicolumn{16}{|c|}{ \% Energy contributions without alcohol } \\
\hline Protein & 13.3 & 15.4 & 17.5 & 13.2 & DU & 15.9 & 12.8 & 11.0 & 13.1 & 12.0 & 14.1 & 19.0 & 12.8 & 13.5 & 16.4 \\
\hline Carbohydrates & 46.3 & 51.0 & 47.1 & 47.4 & DU & 49.8 & 55.0 & 52.3 & 52.3 & 41.5 & 44.6 & 41.2 & 47.5 & 49.3 & 47.6 \\
\hline Fat & 40.3 & 36.0 & 33.9 & 39.4 & DU & 33.8 & 32.2 & 36.6 & 35.3 & 46.5 & 41.3 & 38.5 & 39.5 & 38.0 & 35.4 \\
\hline MUFA & DU & 14.5 & 17.0 & DU & DU & 12.2 & DU & 14.4 & DU & DU & 18.8 & 17.4 & DU & 15.9 & 15.5 \\
\hline PUFA & DU & 6.1 & 5.0 & DU & DU & 5.0 & DU & 6.2 & DU & DU & 6.8 & 4.7 & DU & 6.3 & 4.9 \\
\hline SAT & DU & 12.1 & 11.9 & DU & DU & 15.6 & DU & 13.4 & DU & DU & 12.0 & 12.7 & DU & 12.4 & 13.4 \\
\hline
\end{tabular}

* Mean, average of the four countries. MUFA, monounsaturated fatty acids; PUFA, polyunsaturated fatty acids; SAT, saturated fatty acid. Other abbreviations as in table 1 .

with all the dietary methods (table 2 ). With respect to the nutritional differences between countries, Poland showed a lower protein intake, and Spain a lower carbohydrate intake, the total fat intake being similar. Estimated saturated fat intake was much higher in Finland, and monounsaturated fat intake was higher in Spain (table 4).

\section{DISCUSSION}

This is the first comparative analysis of the three levels of nutrition information available in different countries: national, household, and individual data. In a nutritional policy context, individual data on food consumption and energy and nutrient intakes provides the most appropriate information as it is segregated by age and sex, thus enabling the identification of high risk population groups. In addition, IDS may provide more suitable information that fits the needs of a national policy. ${ }^{26}{ }^{27}$ However, household and national data may also be very useful in a nutritional policy context as they provide a useful estimate of food and nutrient availability.

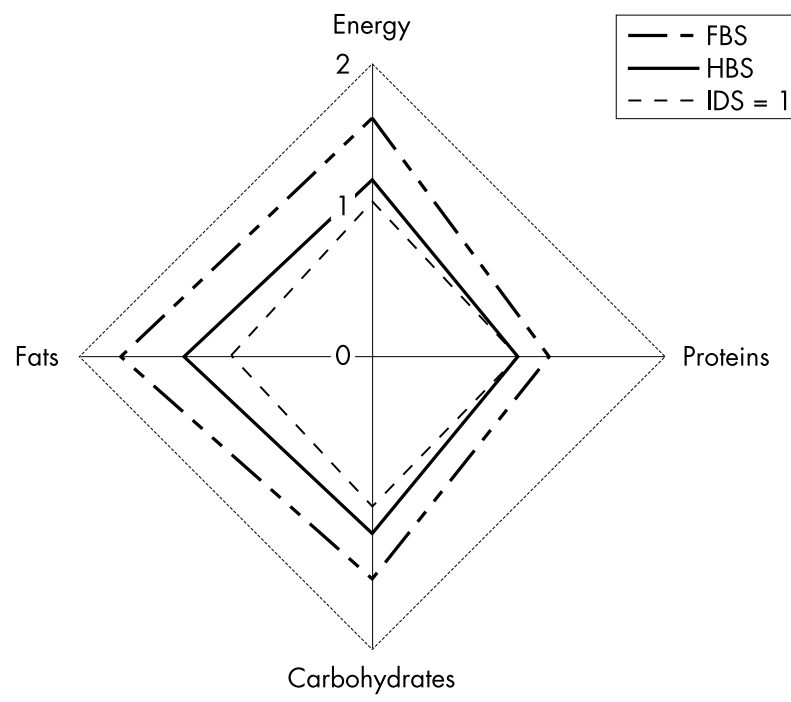

Figure 3 Comparability between the three methods (FBS, HBS, IDS) for energy and macronutrient intake in reference to IDS calculations for the four countries average. Canada, Finland, Poland, and Spain.
Knowing food and nutrient availability is a very important step when developing dietary guidelines, as average individual consumption levels will only be reached if they are available at a national and household level. If available levels of national food consumption are higher than the desirable individual levels, nutrition education may have an important role in the nutrition policy. In contrast, if apparent levels are lower than recommendations, promotion of supply or trade may have an important role in policy development. Also (from a nutrition intervention perspective), the level of food information required will depend on the scope of the intervention. If the aim is to promote dietary changes at the household level via education or price interventions, HBS may be the best dietary tool for monitoring changes. If the scope is to promote national food supply changes by legislation, agricultural incentives, or international trade, FBS would be the most appropriate tool. However, if interventions are aiming to change the nutritional status of individuals by education, fortification, or supplementation, IDS together with anthropometrical and biochemical indicators would be the most adequate tools. ${ }^{26-28}$

While FBS and HBS can easily be compared between countries as, in principle, their reproducibility is high, IDS include several methods (food frequency questionnaires, 24 hour recall, food records, etc), which make comparisons more difficult. However, the methods used in the IDS pooled in this study are similar because they incorporated 24 hour recalls or food records as dietary tools. Although the number of days of observations varies from Finland (three days) to Poland (one day), this factor particularly affects food and nutrient distribution, but not average estimates. ${ }^{29}$

In general, when compared with home food consumption studies, HBS overestimates consumption, ${ }^{30}$ mainly because of storage, consumption of food by visitors, or under-recording of intakes. The analysis of time trends of food availability and consumption show important discrepancies. Additionally, they show different tendencies between availability and consumption for fat and other macronutrients, which should be taken into consideration when interpreting these trends in a policy or research context. ${ }^{31-34}$ This should be particularly relevant in the case of international ecological or correlational studies of diet and disease.

In this study, FBS overestimated food consumption compared with IDS; results between HBS and IDS were quite similar, except for fish, meats, pulses and vegetables, which were underestimated by HBS, and sugar and honey and cereals, which were clearly overestimated. 

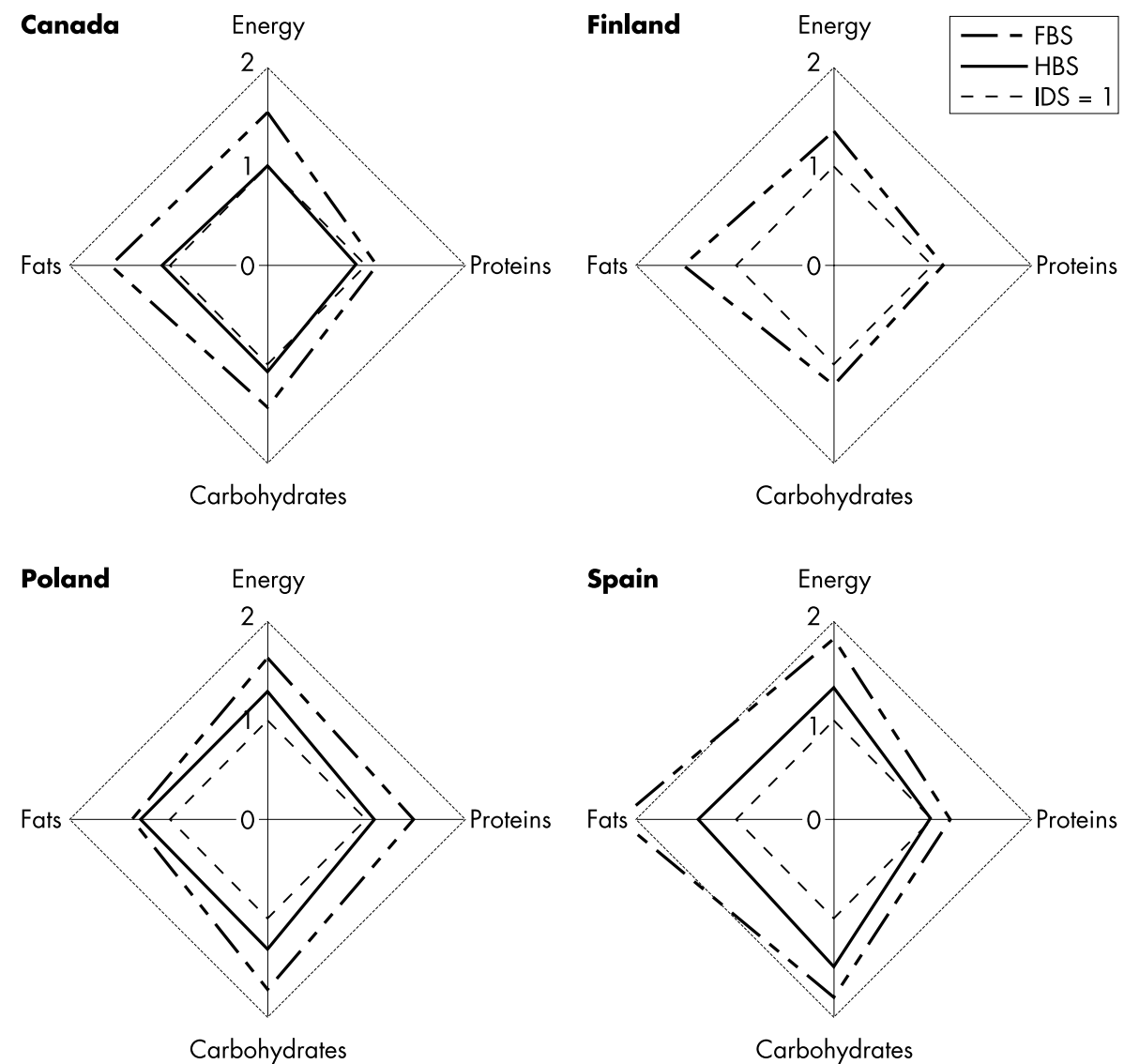

Figure 4 Comparability between the three methods (FBS, HBS, IDS) for energy and macronutrient intake in reference to IDS in Canada, Finland, Poland, and Spain.

\section{Key points}

- Within a food policy context, nutrition planning requires an understanding of food consumption patterns.

- This is the first comparative analysis evaluating the three levels of nutrition information available in different countries: national, household, and individual data.

- The three levels of dietary data provide unique information about food availability and reported intake. Their comparisons are difficult to interpret because each method represents different stages of the food chain.

The differences between the estimates of FBS, HBS, and IDS may be attributable to: (1) differences in method; each methodology has its own advantages and disadvantages, (2) differences in the indicator measured (food availability, food consumption, food waste, etc), and (3) differences in the population group analysed. FBS and HBS comprise the entire population and country, but IDS only consider certain population groups (that is, 20 to 64 years) and regions (that is, Catalonia or Nova Scotia).

It is very difficult to explain if observed differences are attributable to the method, measurement, or population, but usually food availability at national level estimates (FBS) are higher than household levels (HBS), and they are higher than the results from IDS. If results from IDS are greater than results from HBS, differences may be explained by the different age group categories (if the IDS sample excludes children, who consume less fruits and vegetables, IDS may show higher levels of fruit and vegetable consumption than HBS, as has been observed in our study) or the influence of underreporting, which is particularly important among obese people. ${ }^{35}$ If
FBS results are higher than HBS for certain foods, the differences may be explained by the fact that certain products are mainly consumed in the home, but not in institutions or restaurants. It may also indicate weaknesses in both methods, as they are affected by several sources of error.

The three levels of dietary data provide unique information about the availability and reported intake of food in populations and their comparisons are difficult to interpret because each represents different steps of the food chain. The understanding of their relations could play an important part when formulating, evaluating, and monitoring a nutrition policy in a country or region.

\section{ACKNOWLEDGEMENTS}

This study was done in the framework of the Working Group of Comparative Analysis of WHO-CINDI Nutrition Data and is entirely dedicated to the memory of Mukund Nargundkar and Andres Petrasovits, who passed away during this period of research. This group was composed of: Chairman: Lluís Serra-Majem. Participating members: Danielle Brulé; Reina Garcia-Closas; Monic Lalonde; David MacLean; Wolfgang Morgenstern; Mukund Nargundkar; Aulikki Nissinen; Andres Petrasovits; Erik Porfield, Ritva Prattala; Lourdes Ribas; Wlodzimierz Sekula; Agneta Yngve. Observers: Alberto Armas; Carmen Pérez-Rodrigo; Nélida López Armas; Ennie Robertson; L Szponar; Antonia Trichopoulou. The help of Joy Ngo in the supervision of the English version is acknowledged.

\section{Authors' affiliations}

L Serra-Majem, Department of Clinical Sciences, University of Las Palmas de Gran Canaria, Las Palmas de Gran Canaria, Spain L Serra-Majem, L Ribas, R Garcia-Closas, Community Nutrition Research Centre, Science Park of the University of Barcelona, Barcelona, Spain

D MacLean, Department of Community Health and Epidemiology, 
Dalhovile University, Canada

D Brulé, Bureau of Nutritional Sciences, Food Directorate, Ottawa, Canada

W Sekula, National Food and Nutrition Institute, Warsaw, Poland R Prattala, National Public Health Institute, Helsinki, Finland A Yngve, Preventive Nutrition Unit, Karolinska Institutet, Sweden M Lalonde, A Petrasovits, Health Promotion and Programs Branch, Health Canada, Ottawa, Canada

Funding: financial support was provided by: Health Service of the Canary Islands, Health Canada, Food Directorate of Canada, European Office of the World Health Organisation (CINDI and Nutrition Unit), University of Las Palmas de Gran Canaria, Dalhovile University, Polish Institute of Food and Nutrition, Athens School of Public Health, City Hall of Bilbao, Autonomous Goverment of Catalonia, Karolinska Institute, and National Public Health Institute of Finland.

Conflicts of interest: none.

\section{REFERENCES}

1 WHO Regional Office for Europe. Protocol and guidelines: Countrywide Integrated Noncommunicable Disease Intervention (CINDI) Programme. Document EUR/JPC/CIND9402/PB04. Copenhagen: WHO, 1995

2 Morabia A. From disease surveillance to the surveillance of risk factors. Am J Public Health 1996:86:625-7.

3 Frank-Spohrer GC. Community nutrition: applying epidemiology to contemporary practice. Gaithersburg, MD: Aspen Publishers, 1996.

4 Sekula W. Nutrition information systems in Europe. In: Van der Heii, DG, Löwik MRH, Ockhuizen Th, eds. Food and nutrition policy in Europe. Wageningen: Pudoc Scientific Publishers, 1993:101-12.

5 Serra-Majem L, Ribas L, Lloveras G, et al. Changing patterns of fat consumption in Spain. Eur J Clin Nutr 1993;47 (suppl 1):S13-20.

6 Keys AB. Seven countries: A multivariate analysis of death and coronary heart disease. Cambridge, MA: Harvard University Press, 1980.

7 Huijbregts PP, Feskens EJ, Rasanen L, et al. Dietary intake in five ageing cohorts of men in Finland, Italy and the Netherlands. Eur J Clin Nutr 1995:49:852-60.

8 WHO MONICA Project Principal Investigators. The World Health Organisation MONICA Project (Monitoring Trends and Determinants in Cardiovascular Disease): a major international collaboration. J Clin Epidemiol 1988:41:105-14.

9 Riboli E. Nutrition and cancer: background and rationale of the European Prospective Investigation into Cancer and Nutrition (EPIC). Ann Oncol 1992;3:783-91.

10 Van't Hof MA, Hautvast JG, Schroll M, et al. Design, methods and participation. Euronut SENECA investigators. Eur J Clin Nutr 1991;45 (suppl 3):S5-22.

11 Kardinaal AF, van't Veer P, Kokl FJ, et al. EURAMIC Study: antioxidants, myocardial infarction and breast cancer. Design and main hypotheses. Eur J Clin Nutr 1993:47 (suppl 2):S64-72.

12 Friedman GD, Cutter GR, Donahue RP, et al. CARDIA: study design, recruitment, and some characteristics of the examined subjects. J Clin Epidemiol 1988;41:1105-16

13 Centers for Disease Control and Prevention. The Behavioural Risk Factor Surveillance system: survey design, execution, and use. Atlanta, GA: Centers for Disease Control and Prevention, 1996.

14 The ERICA Research Group. The CHD risk-map of Europe. The 1st report of the WHO-ERICA Project. Eur Heart J 1988;9 (suppl 1):S1-36.

15 Morabia A, Beer-Borst S, Hercberg S. Locally based surveys, unite! The EURALIM example. EURALIM Study Group. European information Campaign on Diet and Nutrition. Am J Public Health 1998;88:1 153-5.
16 Trichopoulou A, Kanellou A, Lagiou P, et al. Integration of nutritional data on household budget surveys in European countries. Proc Nutr Soc 1996;55:699-704

17 FAO. FAOSTAT-PC, Food Balance Sheets 1997. Rome: FAO, 1998

18 Kafatos A, Corrington A, eds. Eurodiet reports and proceedings. Public Health Nutr $2001 ; 4: 265-337$.

19 Beer-Borst S, Hercberg S, Morabia A, et al. Dietary patterns in six European populations: results from EURALIM, a collaborative European data harmonization and information campaign. Eur J Clin Nutr 2000;54:253-62

20 Trichopoulou A, ed. Methodology and public health aspects of dietary surveillance in Europe: the use of Household Budget Surveys. Eur J Clin Nutr 1992;46 (suppl 5):S1-153.

21 Karpinski KF, Nargundkar MS. Nova Scotia Nutrition Survey Methodology Report. Report No E451311-0010. Canada: Health and Welfare Canada, 1992

22 Kleemola P, Virtanen M, Pietinen P. The 1992 Dietary Survey of Finnish Adults. Helsinki: Publications of the National Public Health Institute, 1994.

23 Szponar L, Rychlik E. Nutrition made and Nutrition status of boys and men in Poland. National Food and Nutrition Institute. Polish Journal of Human Nutrition and Metabolism 1996; (suppl 2):S1-37.

24 Szponar L, Ryclilik E, Respondek V. Nutrition made and nutrition status of girls and women in Poland. National Food and Nutrition Institute. Polish Journal of Human and Metabolism 1996; (suppl 2):S38-94.

25 Serra-Majem L, Ribas Barba L, García Closas R, et al. Avaluació de l'estat nutricional de la població catalana (1992-93). Avaluació dels hàbits alimentaris, el consum d'aliments, energia i nutrients, i de l'estat nutricional mitjançant indicadors bioquimics $i$ antropomètrics. [The evaluation of nutritional status in Catalonia, Spain (1992-

1993)Evaluation of the dietary intake, food consumption, energy and nutrients and the nutritional status through biochemical and anthropometric markers]. Barcelona: Generalitat de Catalunya, Departament de Sanitat i Seguretat Social, 1996.

26 Pelletier DL, Habicht JP. Continuing needs for food consumption data for public health policy. J Nutr 1994;124 (suppl 9):S1846-52.

27 Lowik MR. Possible use of food consumption surveys to estimate exposure to additives. Food Addit Contam 1996;14:427-41.

28 Serra-Majem L. Hacia una alimentación saludable. [Towards a healthy diet]. In: Dardet CA, Colomer C eds. Promoción de la salud y cambio social. [Health promotion and social change]. Barcelona: Masson, 2001:191-211.

29 Willett W, ed. Nutritional epidemiology. 2n edn. New York: Harvard University Press, 1998

30 Nelson M, Dyson PA, Paul AA. Family food purchases and home food consumption: comparison of nutrient contents. Br J Nutr 1985 54:373-87.

31 Crane NT, Lewis CJ, Yetley EA. Do time trends in food supply levels of macronutrients reflect survey estimates of macronutrient intake? Am J Public Health 1992;82:862-6.

32 Rodriguez-Artalejo F, Banegas JR, Graciani A, et al. Food supply versus household survey data: nutrient consumption trends for Spain, 1958-1988. Eur J Epidemiol 1996;12:367-71.

33 Anonymous. Food that "disappears" into the food supply: is it all consumed?. Nutr Rev 1993;51:206-8.

34 Sasaki S, Kesteloot $\mathrm{H}$. Value of Food and Agriculture Organization data on food-balance sheets as a data source for dietary fat intake in epidemiologic studies. Am J Clin Nutr 1992;56:716-23.

35 Becker W, Foley S, Shelley E, et al. Energy under-reporting in Swedish and Irish dietary surveys: implications for food-based dietary guidelines. Br J Nutr 1999;81 (suppl 2):S127-31. 